\title{
Prevalence of anemia in pregnant mothers and their outcome: a study in a semi urban area
}

\section{Juvvadi Srilatha*}

Department of Obstetrics and Gynecology, Mallareddy Institute of Medical Sciences, Hyderabad,Telangana, India

Received: 13 October 2017

Accepted: 16 October 2017

\section{*Correspondence:}

Dr. Juvvadi Srilatha,

E-mail: juvvadisrilatha@gmail.com

Copyright: (C) the author(s), publisher and licensee Medip Academy. This is an open-access article distributed under the terms of the Creative Commons Attribution Non-Commercial License, which permits unrestricted non-commercial use, distribution, and reproduction in any medium, provided the original work is properly cited.

\begin{abstract}
Background: One of the most common disorders associated with nutritional deficiencies is anaemia. The etiology of anemia during pregnancy among women in developing countries is multifactorial and varies by geographic region. Hence this study was conducted to assess the prevalence of anemia among the pregnant women in our geographical area along with the outcome.

Methods: The patients age, weight, BMI, parity, etc were noted and blood was collected for blood investigations which included random sugar levels, complete blood picture apart feom haemoglobin levels. Hemoglobin was calculated by Sahli's method and classified according to the WHO classification for pregnant women.

Results: The predominant age group of the 486 patients was 20-24 years, followed by 25-29 years. 291 out of the 486 patients $(59.9 \%)$ were anemic and $40.1 \%$ of the patients were non anemic. $19.8 \%$ of the patients had mild anemia, $33.3 \%$ of the patients had moderate anemia, and $6.8 \%$ of the patients had severe anemia.

Conclusions: Information and interaction, and good nutritional diet and medication is important to reduce the incidences of anemia and thereby the morbidity and mortality associated with it.
\end{abstract}

Keywords: Anemia, Foetal outcome, Pregnant women

\section{INTRODUCTION}

One of the most common disorders associated with nutritional deficiencies is anaemia. It has been estimated by WHO that about one third of the population throughout the world are affected by this disorder. ${ }^{1}$

Around $14 \%$ of the pregnant women in the developed countries and $55 \%$ in the developing countries are affected, with $65-75 \%$ seen among the pregnant women in the Indian subcontinent. ${ }^{2}$ This results in severe morbidity and mortality among the women and low birth weight and death among the new born. Many of the women are anaemic before the conception, leading to a prevalence of anaemia among the no pregnant women also which is estimated to be around $50 \%$. $^{3}$
The prevalence in India is very high and contributes to about $80 \%$ of maternal deaths due to anemia in south Asia. This could also be due to size of the population. ${ }^{4}$

Anaemia begins in childhood, worsens during adolescence in girls and gets aggravated during pregnancy. Surveys conducted in India have shown that $70 \%$ of the preschool children were anemic and so were over $70 \%$ of the pregnant women and adolescent girls in the country. ${ }^{5-7}$

The etiology of anemia during pregnancy among women in developing countries is multifactorial and varies by geographic region. Hence this study was conducted to assess the prevalence of anemia among the pregnant women in our geographical area along with the outcome. 


\section{METHODS}

This study was conducted by the department of Gynecology at PK Das institute of Medical sciences from from Sep 2014 to Aug 2015. 486 women who had come to our OP at $20-26$ weeks of pregnancy were included in the study. Informed consent was taken from all the patients after explaining the complete nature of the study. All the patients were interviewed with regard to their demographic and socioeconomic status and pregnant history. The patients age, weight, BMI, parity, etc were noted and blood was collected for blood investigations which included random sugar levels, complete blood picture apart feom haemoglobin levels. Hemoglobin was calculated by Sahli's method and classified according to the WHO classification for pregnant women. Mild anemia was classified if the concentration was 9.0 to 10.9 gm $\%$, moderate, if it was 7.0 to $8.9 \mathrm{gm} \%$ and severe in case of hemoglobin levels of $>7 \mathrm{gm} \%$. Values above 11 gm\% were considered to be non anemic. Non anemic and non pregnant women were excluded from this study. All the patients with mild and moderate anaemia were given oral iron and folate, B12 tablets. Severely anaemic patients were admitted for blood transfusion.

\section{RESULTS}

The predominant age group of the 486 patients was 20-24 years, followed by $25-29$ years. 28 patients $(5.8 \%)$ were below the age of 20 years and $3(0.6 \%)$ were above 40 years. However, majority of the patients who were anaemic belonged to the 35-39 years age group followed by 35-39 age group. Even in the patients who were $<20$ years old, $82.1 \%$ of them were anemic (Table 1 ).

Table 1: Age wise distribution of patients.

\begin{tabular}{|lll|}
\hline Age (in years) & Number $(\%)$ & Anemic \\
\hline$\leq 19$ & $28(5.8 \%)$ & $23(82.1 \%)$ \\
\hline $20-24$ & $185(38.1 \%)$ & $98(53 \%)$ \\
\hline $25-29$ & $173(35.6 \%)$ & $89(51.4 \%)$ \\
\hline $30-34$ & $61(12.6 \%)$ & $48(78.7 \%)$ \\
\hline $35-39$ & $36(7.4 \%)$ & $31(86.1 \%)$ \\
\hline$\geq 40$ & $3(0.6 \%)$ & $2(66.6 \%)$ \\
\hline
\end{tabular}

291 out of the 486 patients $(59.9 \%)$ were anemic and $40.1 \%$ of the patients were non anemic (Figure 1).

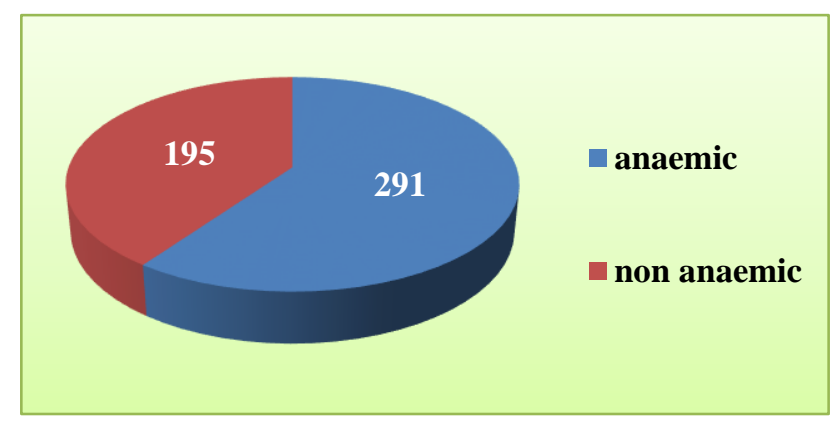

Figure 1: Incidence of anemia.
$40.1 \%$ of the patients were non anemic. Based on the WHO classification, $19.8 \%$ of the patients had mild anemia, $33.3 \%$ of the patients had moderate anemia, and $6.8 \%$ of the patients had severe anemia. Out of the total 228 primiparous women, $51.8 \%$ were non anemic, $18.4 \%$ had mild anemia, $26.8 \%$ had moderate and $3.1 \%$ had severe. Among the multiparous women, $29.8 \%$ were non anemic, while $20.9 \%, 39.1 \%$ and $10.1 \%$ of them had mild, moderate and severe anemia respectively (Table 2).

Table 2: Type of anemia among the patients.

\begin{tabular}{|llcl|}
\hline Type & Primi & Multiparous & $\begin{array}{l}\text { Number } \\
(\%)\end{array}$ \\
\hline $\begin{array}{l}\text { Non Anaemic } \\
(>11 \mathrm{gm} \%)\end{array}$ & $\begin{array}{l}118 \\
(51.8 \%)\end{array}$ & $77(29.8 \%)$ & $\begin{array}{l}195 \\
(40.1 \%)\end{array}$ \\
\hline $\begin{array}{l}\text { Mild } \\
\text { 9-10.9 gm\% }\end{array}$ & $\begin{array}{l}42 \\
(18.4 \%)\end{array}$ & $54(20.9 \%)$ & $\begin{array}{l}96 \\
(19.8 \%)\end{array}$ \\
\hline $\begin{array}{l}\text { Moderate } \\
7-8.9 \text { gm\% }\end{array}$ & $\begin{array}{l}61 \\
(26.8 \%)\end{array}$ & $101(39.1 \%)$ & $\begin{array}{l}162 \\
(33.3 \%)\end{array}$ \\
\hline $\begin{array}{l}\text { Severe } \\
<7 \mathrm{gm} \%\end{array}$ & $7(3.1 \%)$ & $26(10.1 \%)$ & $33(6.8 \%)$ \\
\hline Total & $\begin{array}{l}228 \\
(100 \%)\end{array}$ & $258(100 \%)$ & 486 \\
\hline
\end{tabular}

Most of the women with severe anemia has children with less than $2 \mathrm{~kg}$ weight, while those with mild and moderate anemia predomiantly delivered babies of $2-2.5 \mathrm{~kg}$ weight (Table 3).

Table 3: Birth weight of the newborn.

\begin{tabular}{|lllll|}
\hline Weight & $\begin{array}{l}\text { Non } \\
\text { anaemic }\end{array}$ & Mild & Moderate & Severe \\
\hline$<2 \mathrm{Kg}$ & 12 & 26 & 31 & 21 \\
& $(6.2 \%)$ & $(27.1 \%)$ & $(19.1 \%)$ & $(63.4 \%)$ \\
\hline $2-2.5$ & 36 & 59 & 97 & 8 \\
$\mathrm{Kg}$ & $(18.5 \%)$ & $(61.5 \%)$ & $(59.9 \%)$ & $(24.2 \%)$ \\
\hline$>2.5$ & 147 & 11 & $34(21 \%)$ & 4 \\
$\mathrm{Kg}$ & $(75.4 \%)$ & $(11.5 \%)$ & & $(12.1 \%)$ \\
\hline
\end{tabular}

The major consequence observed due to anemia was the low birth weight of the new born.

$36.4 \%$ of the babies were preterm in case of patients with severe anemia, while it was $2.1 \%$ ans $3.7 \%$ in the case of mild and moderate anemia. $7(21.2 \%)$ of the babies with severely anemic mothers were either still born or died within the first week of birth (Table 4).

\section{DISCUSSION}

Although many control programs for anaemia have been implemented for many years, the magnitude of the problem remains the same with no significant changes even after folic acid and iron supplements.

Severe anaemia in pregnancy is said to increase the rate of maternal morbidity and mortality during childbirth. 
In the present study, most of the women were between 20-30 years old, which is the average reproductive age in our geographical area.
A very similar case was observed in a study by Dayal et al were in the predominant age group observed was 20-35 years. $^{8}$

Table 4: Perinatal morbidity in anaemic patients.

\begin{tabular}{|lllll|}
\hline Foetal complications & Mild $(\mathrm{n}=96)$ & Moderate $(\mathrm{n}=162)$ & Severe $(\mathrm{n}=\mathbf{3 3})$ & Total $(\%)(\mathrm{n}=\mathbf{2 9 1})$ \\
\hline Preterm delivery & $2(2.1 \%)$ & $6(3.7 \%)$ & $12(36.4 \%)$ & $20(6.9 \%)$ \\
\hline Low birth weight/IUGR & $85(88.5 \%)$ & $128(79 \%)$ & $22(66.7 \%)$ & $147(50.5 \%)$ \\
\hline Birth asphyxia/sepsis & $4(4.2 \%)$ & $8(4.9 \%)$ & $2(6.1 \%)$ & $14(4.8 \%)$ \\
\hline IUD/ stillbirth/death & $2(2.1 \%)$ & $10(6.2 \%)$ & $7(21.2 \%)$ & $19(6.5 \%)$ \\
\hline
\end{tabular}

An age group of aboe 30 years was found to be predominant in a study by Cheema et al. ${ }^{9}$

The prevalence of anemia among the pregnant women in our population was around $57 \%$. In a literature review by Noronha et al, the overall prevalence of anemia was observed to be from $18-80 \%$, wherein India had the highest prevalence of $80 \% .^{10} \mathrm{~A}$ higher prevalence of $96 \%$ was observed in a study in Pakistan in the Multan area. ${ }^{11}$ In a similar study by Cheema et al, $65.6 \%$ of the cases were found to be anemic. ${ }^{9}$ Similar results were documented by National Family Health Survey and Singh et al. ${ }^{12,13}$ In yet another study, a lower prevalence of anemia $\left(27.9 \%\right.$ was reported. ${ }^{14}$

Normally, women with mild anemia in pregnancy are said to have decreased work capacity, and would not be able to earn their livelihood if their work involves physical labor. However, these patients may not have any adverse effects in their period of pregnancy as well as labour. Women with moderate anaemia have substantial reduction in work capacity and may find it difficult to cope with household chores and child care. They are more susceptible to infections and recovery from infections may be prolonged.

Premature births are more common in women with moderate anaemia. They deliver infants with lower birth weight and perinatal mortality is higher in these babies. The cardiac output is raised even at rest, the stroke volume is larger and the heart rate is increased. Palpitation and breathlessness even at rest are symptoms of these changes. ${ }^{15,16}$ These compensatory mechanisms are inadequate to deal with the decrease in $\mathrm{Hb}$ levels. Anaemia directly causes 20 per cent of maternal deaths in India and indirectly accounts for another 20 per cent of maternal deaths. ${ }^{17}$

In the present study, the number of women with mild anemia was $96(19.8 \%)$, moderate was $162(33.3 \%)$ and severe was $33(6.8 \%)$. In a study by Cheema et al., mild anemia was observed in $60 \%$ of the cases, moderate in $30.4 \%$ and severe anaemia in $9.6 \%$. They found dietary pattern to significantly influence the anemia status of the patient. Women following non vegetarian $(50 \%)$ or mixed pattern $(28.3 \%)$ of diet were less anaemic as compared to women who were exclusively on vegetarian diet. ${ }^{9}$ A similar study by Dayal et al reported a prevalence of $19.19 \%$ mild, $41.4 \%$ moderate and $2.47 \%$ severe anemia in pregnant women. ${ }^{8}$ A similar condition was observed in Pakistan in which majority of the cases had mild anaemia $(75.0 \%)$, moderate anaemia $(14.8 \%)$ and severe anaemia $(0.7 \%) .{ }^{18}$ Similarly, report from India in 2010 also showed the majority $(50.9 \%)$ demonstrated moderate anaemia and followed by mild (30.17\%) and severe anaemia (18.9\%), respectively. ${ }^{19}$

The most common outcome of the newborn was low birth weight followed by preterm delivery. The risk of preterm delivery was more in anaemic group and increased with severity from 50 to $70 \%$ which was reported in various studies. ${ }^{20-22}$ However, a large Californian study, Klebanoff et al showed a doubled risk of preterm delivery with anaemia. ${ }^{23}$

It is generally believed that anaemia in pregnancy increases with rising parity, due to repeated drain on iron stores. ${ }^{24}$ However, in this study, there was no significant difference in the primi and the multiparous women. An inverse relationship between parity and anaemia was observed by few researchers as the percentage of anaemic pregnant women decreased as parity increased. ${ }^{25,26}$ The possible reasons for this was described as an increased awareness of the value of drugs and good diet with increasing parity as well as increased interaction with other pregnant women at the clinic.

\section{CONCLUSION}

In countries such as India, which have a high number of population as well as poor nutritional conditions, anemia is very predominant and adversely affects both maternal and foetal outcome. It is directly linked with low birth weight premature delivery and severe morbidity and mortality. Thus, proper information and interaction, and good nutritional diet and medication is important to reduce the incidences of anemia and thereby the morbidity and mortality associated with it. 
Funding: No funding sources

Conflict of interest: None declared

Ethical approval: The study was approved by the Institutional Ethics Committee

\section{REFERENCES}

1. WHO. 2004. Micronutrient deficiency: Battling iron deficiency anaemia: the challenge. Available at http://www.who.int/ nut/ida.htm. Accessed on April 24, 2008

2. DeMayer EM, Tegman A. Prevalence of anaemia in the World. World Health Organ Qlty. 1998;38:30216.

3. World Health Organization. WHO/NUT/MCM/92.2. WHO; Geneva. The prevalence of anemia in women: A tabulation of available information. $2^{\text {nd }}$ ed. Geneva: World Health Organization;1992. Available at http://www.who.int/iris/handle/10665/58994

4. Ezzati M, Lopus AD, Dogers A, Vander HS, Murray C. Selected major risk factors and global and regional burden of disease. Lancet. 2002;360:134760.

5. IIPS National Family Health Survey 1998-99 (NFHS-2): Available at http://www.nfhsindia.org/india2.html. Accessed on September 24, 2008.

6. IIPS. National Family Health Survey 2005-06 (NFHS- 3): Available at http://mohfw.nic.in/nfhsfactsheet.htm. Accessed on September 24, 2008.

7. DLHS on RCH. Nutritional status of children and prevalence of anaemia among children, adolescent grils and pregnant women 2002-2004. Available at http://www.rchindia.org/ nr_india.htm 2006. Accessed on September 24, 2008.

8. Dayal S, Dayal A. Prevalence and consequences of anaemia in pregnancy. Int $\mathrm{J}$ Med Res Rev. 2014;2(4):296-9.

9. Cheema HK, Bajwa BS, Kaur K, Joshi H. Prevalence and possible risk factors of anaemia in different trimesters of pregnancy. IJCMR. 2016;3(4):1194-7.

10. Noronha JA, Khasawneh EA, Seshan V, Ramasubramianian S, Raman S. Anemia in Pregnancy - Consequences and challenges: A review of literature. J South Asian Fed of Obstet Gyncol. 2012;4(1):64-70.

11. Mahe-Muhir A. A study of anemia in pregnancy women of railway colony Multan, Pakistan. J Med Res. 2004;4(1).

12. Ministry of Health and Family Welfare Government of India. National Family Health Survey (NFHS-3) 2005-2006. Available at http://pdf.usaid.gov/ pdf_docs/PNADK385.pdf. Accessed on Feb $9^{\text {th }}$ 2016.

13. Singh AB, Kandpal SD, Chandra R, Srivastava VK, Negi KS. Anemia amongst pregnant and lactating women in District Dehradun. Indian J Prev Soc Med. 2009;1:19-22.

14. Kefiyalew F, Zemene E, Asres Y, Gedefaw L. Anemia among pregnant women in Southeast Ethiopia: prevalence, severity and associated risk factors. BMC Research Notes. 2014 Nov 3;7(1):771.

15. Kalaivani K. Prevalence and consequences of anaemia in pregnancy. Indian $\mathrm{J}$ Med Res. 2009; 130:627-633.

16. Prema K, Neela KS, Ramalakshmi BA. Anaemia and adverse obstetric out come. Nutr Rep Int. 1981;23:637-43.

17. Maternal Mortality in India 1997-2003, Registrar General of India. Available athttp://www.censusindia.net/. Accessed on December 15, 2008.

18. Levy A, Fraser D, Katz M, Mazor M, Sheiner E. Maternal anaemia during pregnancy is an independent risk factor for low birth weight and preterm delivery. Eur J Obstet Gynecol Reprod Biol. 2005;122(2):182-6.

19. Vijaynath 1, Jitendra 1, Ramesh P, Abhishek P. Prevalence of anemia in pregnancy. Indian J Appl Basic Med Sci. 2010;12:23-35.

20. Jain P, Kural M, Joshi T. Maternal and fetal outcome in cases of severe anaemia with pregnancy in rural setup. Int J Med Appl Sci. 2013;2(3):318-33.

21. Bakhtiar UJ, Khan Y, Nasar R. Relationship between maternal haemoglobin and perinatal outcome. Rawal Med J. 2007;32(2):102-4.

22. Rani U, Gupta J, Gupta R, Aggarwal K. Maternal anaemia and its severity: an independent risk factor for preterm delivery and adverse neonatal outcome. Int J Reprod Contracept Obstet Gynecol. 2014 Jun;3(2):325-9.

23. Klebanoff MA, Shiono PH, Selby JV, Trachtenberg AI, Graubard BI. Anemia and spontaneous preterm birth. Am J Obstet Gynecol. 1991;164:59-63.

24. Adinma JB, Ikechebelu JI, Onyejimbe UN, Amilo G, Adinma E. Influence of antenatal care on the haematocrit value of pregnant Nigerian Igbo women. Tropic J Obstet Gynecol. 2002;19(2):68-70.

25. F. I. Buseri, E. K. Uko, Z. A. Jeremiah, and E. A. Usanga, "Prevalence and risk factors of anaemia among pregnant women in Nigeria," Open Journal of Hematology, vol. 2, pp. 14-19, 2008.

26. Bukar M, Audu BM, Sadauki HM, Elnafaty AU, Mairiga AG. Prevalence of iron deficiency and megaloblastic anaemia at booking in a secondary health facility in north eastern Nigeria. Nigerian Med J. 2009 Apr 1;50(2):33.

Cite this article as: Srilatha J. Prevalence of anemia in pregnant mothers and their outcome: a study in a semi urban area. Int J Reprod Contracept Obstet Gynecol 2017;6:4886-9. 